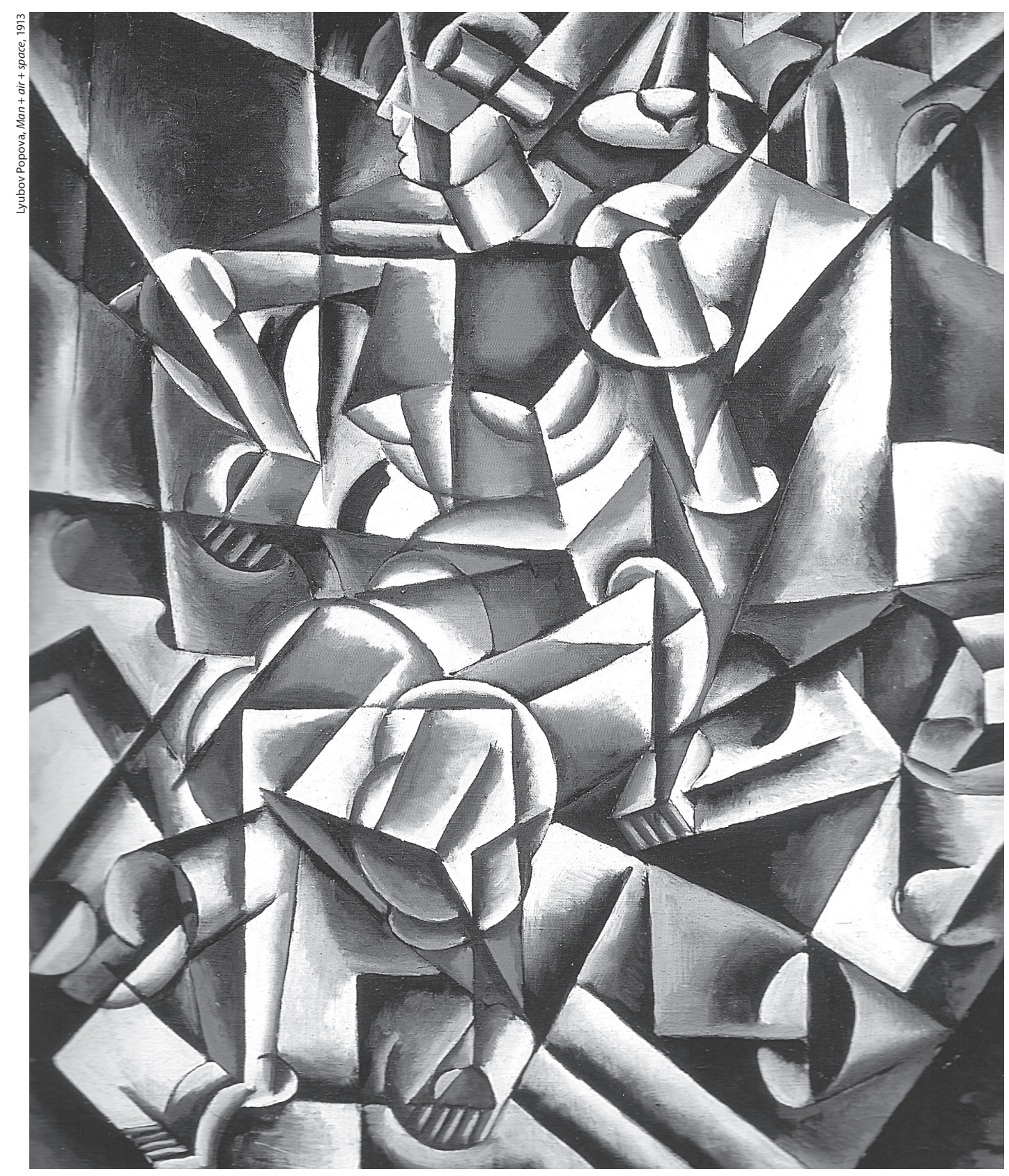

\title{
Conceitos, traduções e visita de V. V. Ivánou
}

Aurora Fornoni Bernardini 


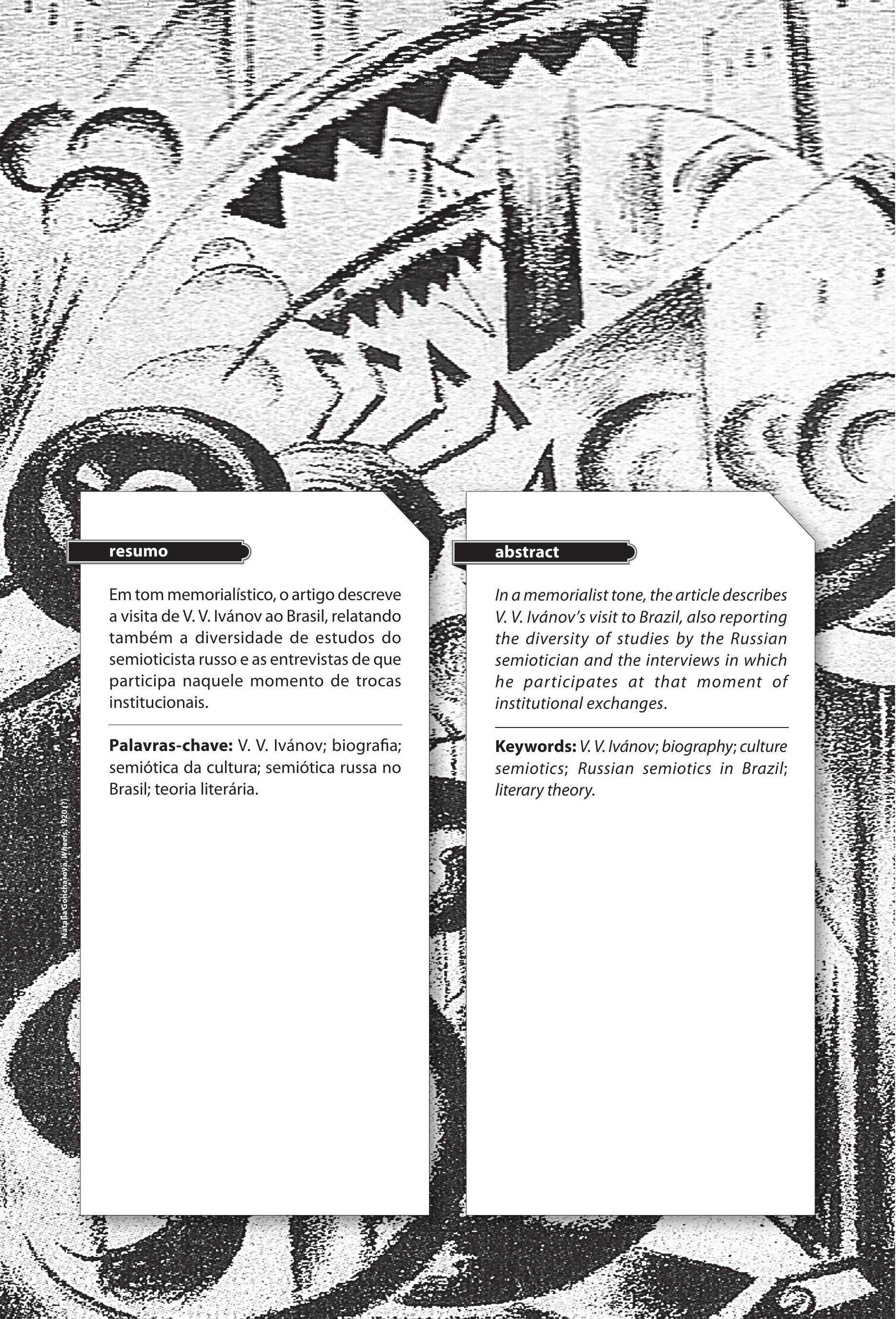




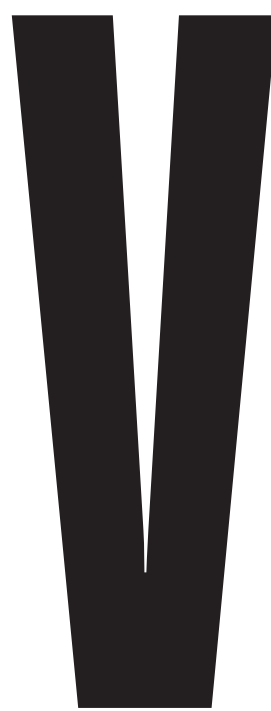

iatchesláv V. Ivánov, eminente professor da MGU, Universidade Estatal de Moscou, foi chefe do Departamento de Tipologia Estrutural do Instituto de Balcanística da Academia de Ciências da URSS, vice-presidente da Associação Internacional de Semiótica e também professor da UCLA, Universidade da Califórnia, Los Angeles, e já lecionou na Universidade de Oxford, Inglaterra, e na Universidade de Stanford.

Crítico, semioticista, antropólogo e linguista de fama mundial, esteve em São Paulo em 1990, a convite do Departamento de Línguas Orientais da USP e com recursos da Fapesp, ocasião em que ministrou uma série de conferências e deslumbrou os ouvintes com sua excepcional cultura. Falou sobre alguns de seus trabalhos, como A história da cultura mundial, $O$ indo-europeu e os indo-europeus (obra em dois volumes, publicada em 1984 na então URSS e pela qual, em parceria com um colega, o linguista georgiano Tamaz Gamkrelidze, obteve o Prêmio Lênin de 1988), A semiótica na Rússia e no Ocidente, Os arquivos de Serguei Eisenstein, Par e impar: o funcionamento dos hemisférios do cérebro, entre outros.

O semioticista trouxe consigo ao Brasil alguns ensaios, que foram traduzidos por uma equipe do curso de Russo da USP, entre os quais: "Antropologia cultural e história da cultura" (1989); "A antiga Ásia Anterior e a migração indo-europeia" (1989, em colaboração com T. Gamkrelidze); "Sobre a escolha da crença na Europa Oriental" (1988) e até mesmo um "Estudo sobre o nome dos metais", o que dá bem a ideia da diversidade de seus interesses.

Participando de uma série de entrevistas, entre as quais uma no IEA/USP, teve ocasião, na época, de expor suas expe-

AURORA FORNONI BERNARDINI é professora titular da Universidade de São Paulo, autora de ensaios e tradutora de, entre outros, V. Khlébnikov, A. Akhmátova e M. Tsvetáieva. 
riências como Deputado do Povo, junto ao Parlamento, na última fase da antiga URSS. Em outra, para a Folha de S. Paulo, perguntada sua opinião sobre a relação política/literatura, reiterou o fato de que, na tradição russa, as grandes "verdades" políticas sempre se expressaram mais facilmente via literatura e que os russos tiveram sempre a tendência para procurar "grandes personalidades" atrás dos escritos e dos versos de escritores e poetas.

Amigo pessoal de Pasternak, cuja casa frequentou até o fim da vida do poeta (eram vizinhos no lugarejo de Pierediélkino, onde uma série de escritores tem suas datchi), teve ocasião de ocupar-se de sua poesia e de escrever alguns ensaios sobre ele. Discorrendo sobre escritores contemporâneos, numa entrevista organizada pelo jornal Folha de S. Paulo, falou de Milan Kundera, que considerou o continuador da prosa filosófica de Broch, Musil e de um Kafka. A Bródski, ele vê como continuador da linha de Maiakóvski, particularmente no que se refere ao ritmo, aos procedimentos e à visada épica. Andriéi Vosnissiênski, que lhe foi apresentado por Pasternak, em cuja casa ele recitou seus primeiros versos, é um dos curiosos exemplos de que tratou Ivánov. $\mathrm{O}$ assunto foi retomado por ele no livro Par e ímpar, em que a personalidade do autor parece ser inferior à sua obra.

"A revisão do passado que os russos estão enfaticamente empreendendo é mais fácil fazê-la através do símbolos", ele nos diz. E aqui a conversa se desloca para o cinema. O cinema em cor simbólica encontra-se, segundo ele, na tradição de Paradjánov, Sokúrov, Bergman, Buñuel e Kurosawa, mostrando-nos coisas que querem dizer

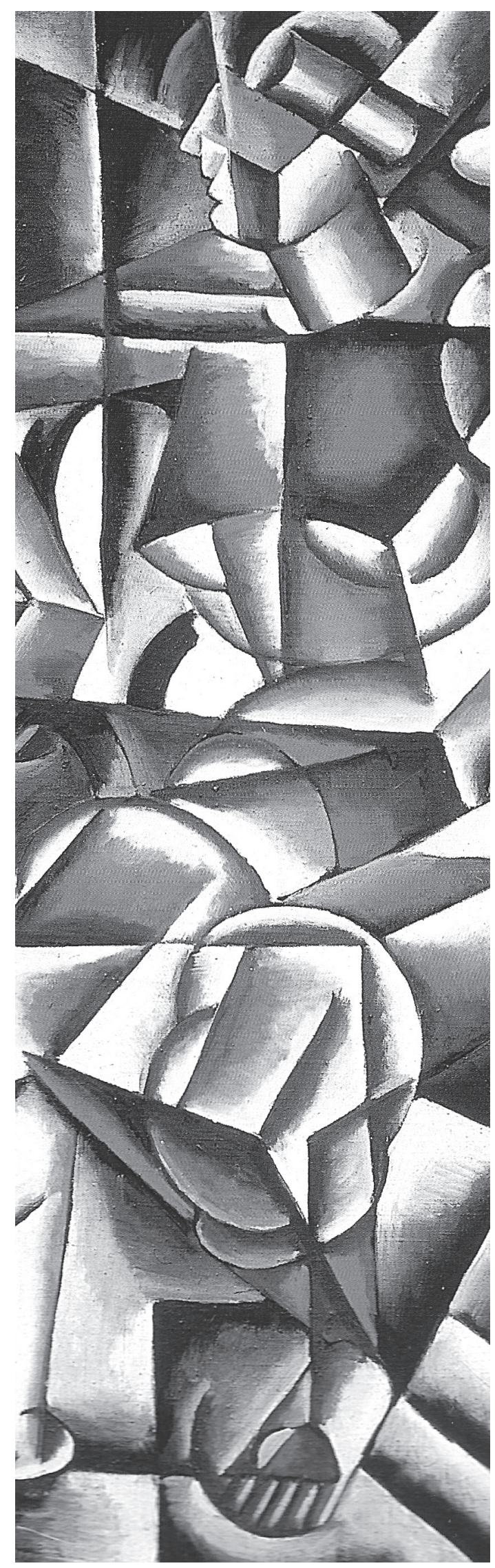


outras. Eisenstein, porém, é diferente, e ainda hoje não é estudado no contexto de suas ideias, nos informa em Dos diários de Serguei Eisenstein e outros ensaios, publicado pela Edusp em 2009. O simbolismo de Tarkóvski também é diferente do de Eisenstein. Seu tipo de composição é outro:

"Tarkóvski tinha o filme inteiro como que visualmente pronto em sua mente (o espectador que via Stalker, por exemplo, podia lembrá-lo visualmente, como uma espécie de poema), mas a dificuldade surgia na hora de filmar. Ele tinha que convencer os atores a acompanhar seu filme mental e como isso era quase impossível, para ele era uma tragédia".

Hoje, na verdade, é o extremo oposto: há gente demais participando da criação de um filme. Como diz:

"O que se faz razoavelmente bem na Rússia de hoje são os documentários (sem falhas otimistas) e a literatura moderna já não é tão importante para documentários: já não se leem Bulgákov, Platónov, mas diferentes tipos de literatura underground. Faz-se muito cinema underground, hoje, no eixo Moscou-Petersburgo (mais em Petersburgo que em Moscou). Outro fenômeno a que se assiste é o da cultura de massa, especialmente via TV. Tudo se transforma em apresentação via TV, e a mais prejudicada é a prosa e seus autores. Mesmo que não tenhamos censura política, passamos a ter outra forma de censura, uma espécie de censura estética. Nosso pensamento filosófico quebrou-se, com raras exceções. Uma delas, a título de registro, é Lídia I. Guinsburg, amiga de Eikhenbaum, que morreu aos 90 anos, após ter passado por tudo. Era

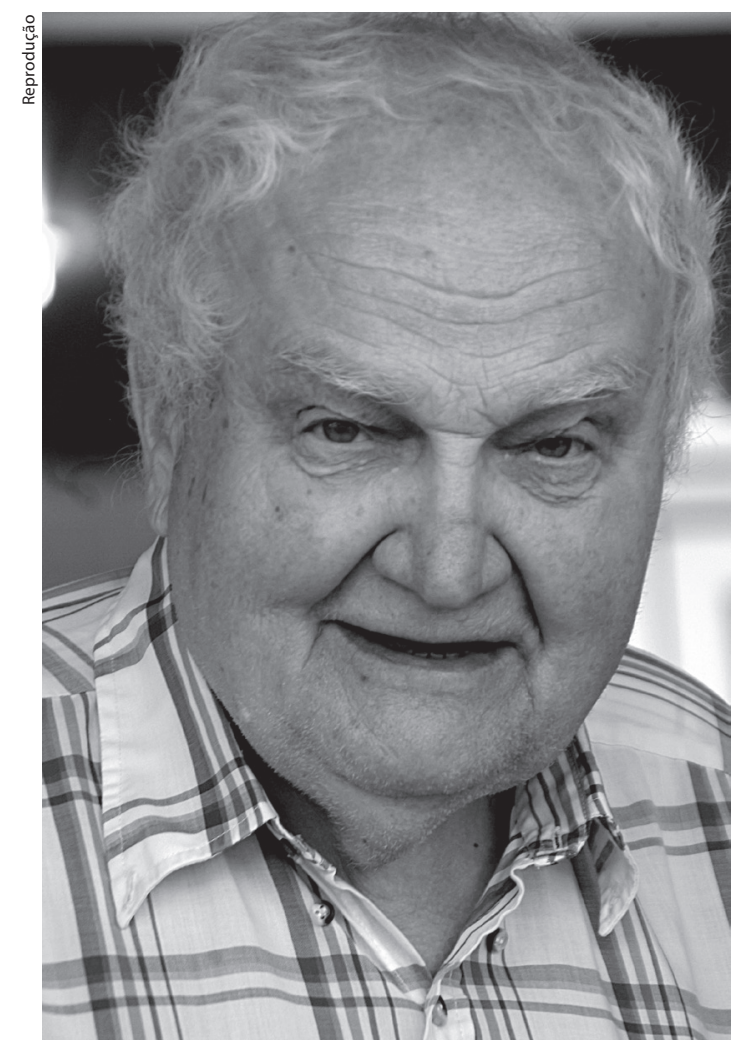

Ivánov na Alemanha, 2013

publicada só na Carélia e somente depois de Stálin escreveu suas obras teóricas".

E Ivánov continua:

"Voltando à literatura, com Isaac Bábel, que eu considero um dos escritores mais originais, tenho uma curiosa ligação biográfica: meu irmão mais velho é filho dele e guarda umas cem cartas, que ainda não sabe se consentirá ou não em publicar. Até o fim, Bábel não podia admitir que iria morrer. Quando foi preso, foram sequestrados os manuscritos do livro sobre a KGB que ele estava escrevendo; mesmo hoje, quando é possível visitar esses arquivos, há muitos escritos dele difíceis de encontrar. Foi morto em 1940, quando Béria era ministro do Interior. A revista Ogoniók publicou o dos- 
siê concernente à sua prisão, à tortura, ao julgamento, mas não aos nomes das pessoas que denunciaram Bábel à polícia secreta”.

Esses e outros depoimentos são da maior importância. Servem como exemplos da amplitude dos interesses de Ivánov e de sua rápida aclimatação no Brasil.

Por fim, segue um roteiro do curso de pós-graduação em Literatura Comparada e Antropologia que ele se dispunha a ministrar na USP no segundo semestre de 1993, não tivessem surgido problemas de saúde a impedi-lo:

1. Os estudos literários hoje e as novas correntes da historiografia. O tempo histórico e o tempo na literatura. $\mathrm{O}$ espaço e a literatura.
2. Os mitos russos e os cantos épicos (Bilinas). O mito e o conto popular: de Vesselóvski a Propp.

3. A polêmica Lévi-Strauss/Propp e a posição de E. Meletínski. A relação com os estudos de Olga Freydenberg.

4. Os estudos russos sobre os povos paleoasiáticos e os do continente americano.

5. A proto-história dos povos indo-europeus: as migrações.

6. Os conceitos básicos da tipologia contemporânea.

7. Tipologia linguística das línguas indígenas das duas Américas.

8. A Escola de Tártu. Semiótica e mito.

9. Os trabalhos sobre os mitos indianos.

10. O grande dicionário mitológico.

11. Mito, literatura, artes plásticas, cinema.

12. Os mitos contemporâneos. 